Short Communication

\title{
Effect of the Local Damage of a Sulfide Film Formed on Steel Surfaces in $\mathrm{H}_{2} \mathrm{~S}$ Environments
}

\author{
Wei Zhao*
}

College of mechanical and automotive engineering, Qilu University of Technology (Shandong Academy of Sciences), 250353 Jinan, China

*E-mail: zwapple@yeah.net

doi: $10.20964 / 2019.08 .19$

Received: 2 March 2019 / Accepted: 17 May 2019 / Published: 30 June 2019

The electrochemical corrosion behavior of X80 pipeline steel in distilled water with saturated $\mathrm{H}_{2} \mathrm{~S}$ at $323 \mathrm{~K}$ was evaluated, and the corrosion products were characterized. The results showed that mackinawite and cubic FeS were the primary and secondary crystalline phases observed, respectively. In addition, a series of changes in their size and shape occurred during the immersion processes. The sulfide film that formed on the steel surfaces enhanced the corrosion resistance. Moreover, zero resistance ammeter measurements showed that the galvanic effect was introduced between the fresh and sulfide film-covered steel electrodes, and then it decreased, and disappeared, indicating that substantial local corrosion cannot be introduced because of the local damage of the sulfide film.

Keywords: hydrogen sulfide corrosion; electrochemical corrosion; galvanic effect

\section{FULL TEXT}

(C) 2019 The Authors. Published by ESG (www.electrochemsci.org). This article is an open access article distributed under the terms and conditions of the Creative Commons Attribution license (http://creativecommons.org/licenses/by/4.0/). 